\title{
Ring naczyniowy — rzadka przyczyna duszności u pacjenta w podeszłym wieku. Opis przypadku
}

\author{
Vascular ring: a rare cause of dyspnea in an elderly male patient. Case report
}

Praca nie była finansowana

\begin{abstract}
Shortness of breath (dyspnea) and changes present in X-rays of the chest are most frequent symptoms indicating further pulmonary diagnostic. Presented is the case of 71-year-old patient reffered from general practitioner due to exacerbation of dyspnea and abnormalities present in the chest X-ray.The patient has been treated for ischemic heart disease and arrythmia for a couple of years. Three-dimensional CT of the chest revealed a vascular ring of aorta.It is a defect characterized by a faulty flow of large vascular trunks, which built a cardiovascular ring that partially or completely enricle the structure of mediastinum (esophagus, trachea).The observed clinical symptoms are a result of pressure applied to the structure of the mediastinum and its intensity. This cardiovascular defect is diagnosed during early stages of childchood development and for it to be recognized in an adult patient is a casuistic case.
\end{abstract}

Key words: vascular ring, dyspnea, abnormalities in chest X-ray

Pneumonol. Alergol. Pol. 2015; 83: 55-59

\section{Streszczenie}

Najczęstszymi wskazaniami do diagnostyki pulmonologicznej są: duszność i zmiany w obrazie radiologicznym klatki piersiowej. Przedstawiono przypadek 71-letniego pacjenta skierowanego z Poradni Lekarza Rodzinnego z powodu zmian stwierdzonych w obrazie radiologicznym klatki piersiowej oraz nasilającej się duszności. Pacjent od kilku lat leczony z powodu choroby niedokrwiennej mięśnia sercowego i zaburzeń rytmu. W wykonanym badaniu komputerowym klatki piersiowej stwierdzono obecność ringu naczyniowego aorty. Ring naczyniowy aorty jest wadą polegającą na nieprawidłowym przebiegu wielkich pni naczyniowych, które tworzą pierścień naczyniowy otaczający pełnym lub częściowym obwodem struktury śródpiersia (przełyk, tchawicę). Obserwowane objawy kliniczne są skutkiem ucisku i stopnia jego natężenia na narządy śródpiersia. Wada naczyniowa w postaci ringu naczyniowego jest rozpoznawana we wczesnym okresie rozwoju niemowlęcym dziecięcym. Stwierdzenie jej obecności w starszym wieku jest przypadkiem kazuistycznym.

Słowa kluczowe: ring naczyniowy aorty, duszność, zmiany w obrazie radiologicznym klatki piersiowej

Pneumonol. Alergol. Pol. 2015; 83: 55-59

\section{Wstęp}

Najczęstszymi przyczynami kierowania pacjentów do Poradni Pulmonologicznych są zmiany w obrazie radiologicznym klatki piersiowej oraz duszność o nieustalonej przyczynie.

\section{Opis przypadku}

Pacjent, lat 71, został skierowany do Poradni Pulmonologicznej przez Lekarza Rodzinnego z powodu duszności i niejednoznacznego obrazu radiologicznego klatki piersiowej (ryc. 1A, B ). Od

Address for correspondence: dr n. med., mgr inż. chemii Magdalena Orwaldi, Centrum Medyczne HCP w Poznaniu, ul. 28 czerwca 1956 r. 194, e-mail: magorw@esculap.pl DOI: 10.5603/PiAP.2015.0008 

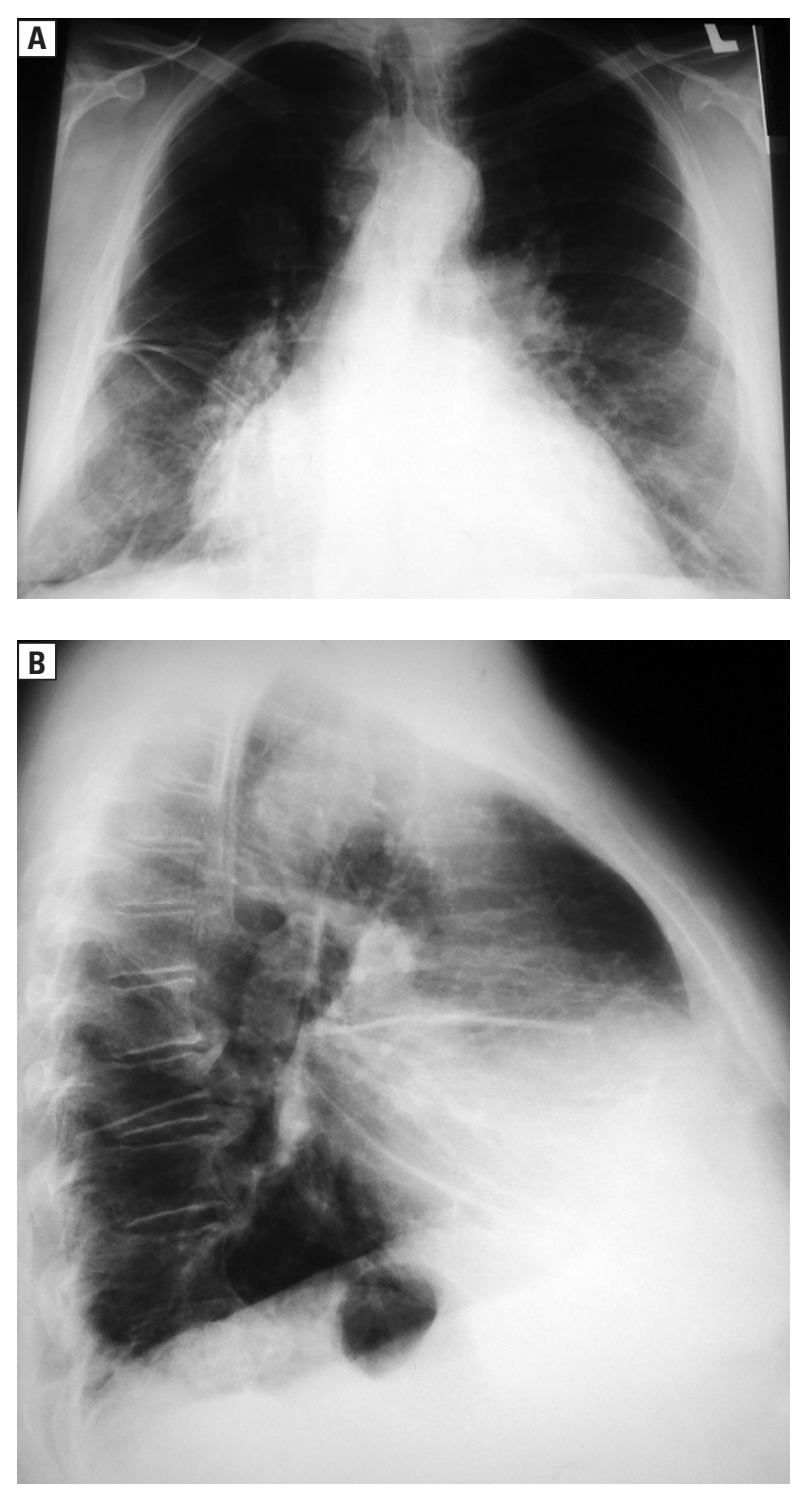

Rycina 1 A, B. RTG klatki piersiowej w projekcji tylno-przedniej i boczej. Powiększona sylwetka serca, poszerzony fuk aorty

Figure 1 A, B. Chest X-ray, posteroanterior and lateral view. The heart are enlarged ,the aortic arch are widened

wielu lat chory pozostawał pod opieką Poradni Kardiologicznej z powodu choroby niedokrwiennej mięśnia sercowego. Pomimo leczenia obserwowano systematyczne pogorszenie stanu ogólnego chorego, a dominującym objawem była pogłębiająca się duszność. W celu wyjaśnienia niejednoznacznego obrazu radiologicznego klatki piersiowej wykonano badanie tomograficzne klatki piersiowej. W badaniu tym stwierdzono obecność wady naczyniowej w postaci ringu naczyniowego aorty otaczającego tchawicę i przełyk, utworzonego przez część wstępującą i zstępującą aorty połączone dodatkowym naczyniem położonym przedkręgosłupowo, zaprzełykowo, część zstępująca aorty przebiegała po stronie prawej (ryc. 2A-D). W badaniu spirometrycznym stwierdzono zaburzenia obturacyjne w stopniu umiarkowanym (ryc. 3), w zapisie EKG - blok lewej odnogi pęczka Hisa.

\section{Omówienie}

Określenie ring naczyniowy - dla konfiguracji naczyń aorty - jako pierwszy wprowadził Robert Gross w 1945 opisując zaobserwowany w 1931 podwójny łuk aorty będący przyczyną duszności u 5 miesięcznego dziecka [1, 2]. Wcześniej, w 1735 roku Hunauld zaobserwował i nazwał pierścieniem naczyniowym zaprzełykowo przebiegającą tętnicę podobojczykową, w 1737 roku Hommel analogicznie określił podwójny łuk aorty, a w 1794 roku Bayford opisał objawy kliniczne wywołane obecnością arteria lusoria (czyli pozaprzełykowo położoną tętnicą podobojczykową).

Zgodnie z obecnie obowiązującą nomenklaturą ring naczyniowy jest wadą wrodzoną polegającą na nieprawidłowym przebiegu wielkich pni naczyniowych - aorty i jej odgałęzień, których efektem jest powstanie pierścienia otaczającego struktury śródpiersia (przełyk, tchawicę). Różne konfiguracje przebiegu tych naczyń opisał, sklasyfikował i opublikował w 1948 roku Edwards [3]. Obecnie w wyniku dalszych modyfikacji i uproszczeń [4] wyróżnia się 4 zasadnicze typy ringów naczyniowych [4, 5].

Najczęściej spotykanym jest podwójny łuk aorty (60-70\% przypadków), który można zaobserwować w dwóch wariantach - pierwszy gdy oba łuki aorty funkcjonują, drugi gdy jeden z nich ulega inwolucji.

Kolejny typ to prawostronny luk aorty z lustrzanym odbiciem układu tętnic odchodzących od łuku aorty i lewostronnym przewodem tętniczym lub więzadłem.

W trzecim typie obserwuje się prawostronny łuk aorty z pozaprzełykowym przebiegiem lewej tętnicy podobojczykowej i lewostronnym przewodem tętniczym lub więzadłem.

W czwartym typie jest lewostronny łuk aorty z pozaprzełykową prawą tętnicą podobojczykową i lewostronnym przewodem tętniczym.

Pierścienie naczyniowe mogą obejmować przełyk i tchawicę pełnym lub częściowym obwodem, tym samym warunkując rodzaj objawów klinicznych jak duszność, stridor, kaszel, zaburzenia połykania oraz stopień ich nasilenia. Obserwowane najczęściej we wczesnym okresie rozwoju — niemowlęcym, dziecięcym sporadycz- 

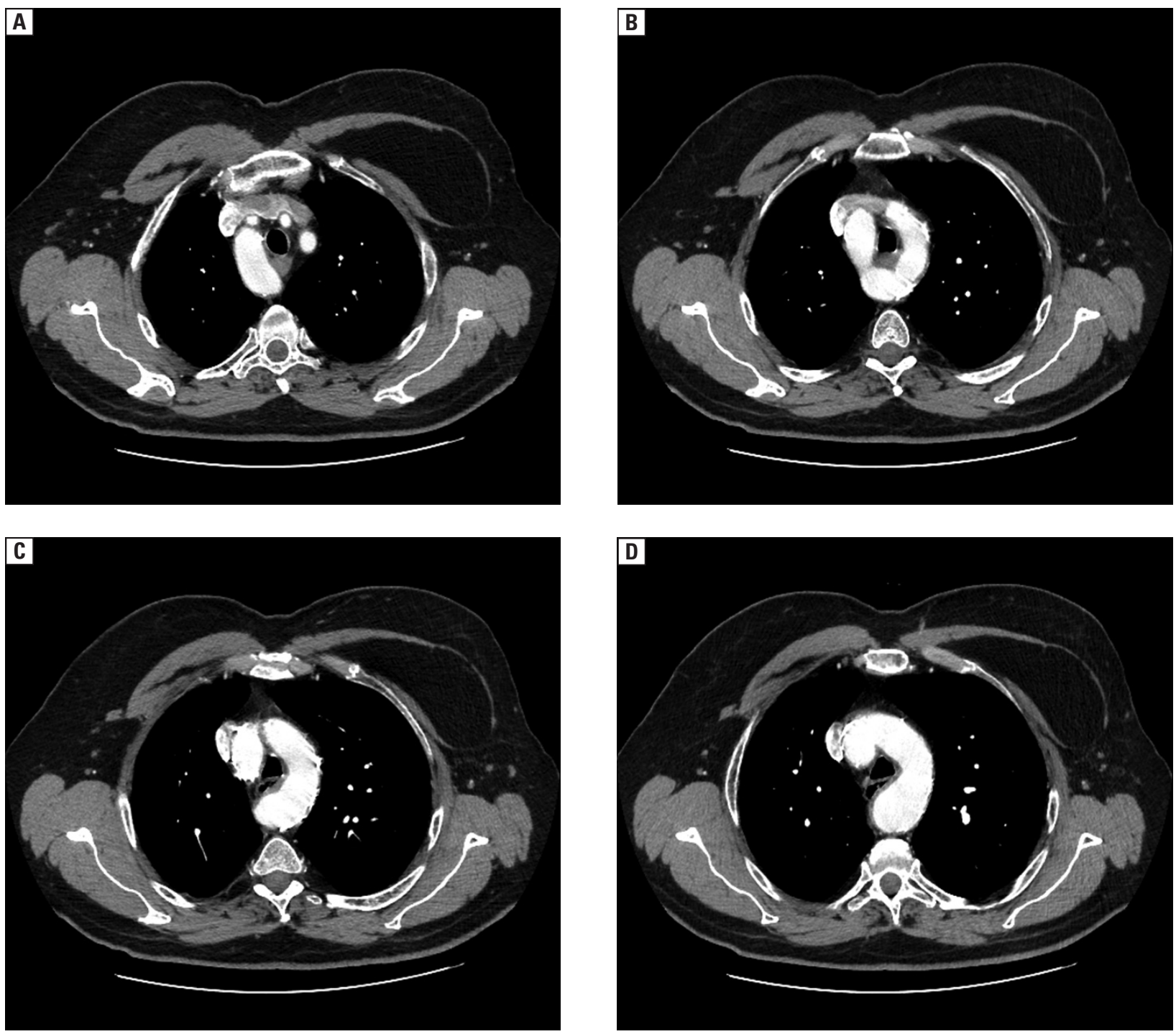

Rycina 2 A, B, C, D. Kolejne skany badania komputerowego przedstawiają aortę otaczającą tchawicę i przełyk. Dodatkowe naczynie łączy część wstępującą i zstępującą aorty.Część zstępująca aorty przebiega po prawej stronie kręgosłupa

Figure 2 A, B, C, D. Computed tomography scans showed the aorta enricle trachea and sophagus. The ascending aorta and descending part of aorta are connected by supplementary artery. The descending aorta is on right part of the vertebral column

nie w życiu płodowym są częstym wskazaniem do interwencji kardiochirurgicznych [6-10].

Znacznie rzadziej anomalię rozpoznaje się w późniejszym wieku. U pacjentów, u których w przebiegu wady naczyniowej dominuje ucisk na tchawicę $[11,12]$, powodując napadową duszność ze słyszalnymi świstami, często rozpoznawana jest astma oskrzelowa.

Mimo leczenia, nie uzyskuje się jednak kontroli objawów [11]. Jeżeli występuje ucisk na przełyk i daje częściową niedrożność górnego odcinka przewodu pokarmowego, częstym objawem są wymioty. W opisywanym przypadku ring naczyniowy był utworzony w rzadko opisywanej konfiguracji - części wstępująca i zstępująca aorty były połączone dodatkowym naczyniem.
Skutkiem takiego połączenia naczyń mogą zaburzenia rytmu, bóle zamostkowe, duszność. Pacjenci z tego typu konfiguracją ringu naczyniowego są obiektem obserwacji lub nawet interwencji kardiologicznej [13-16]. W opisywanym przypadku uzyskanie pełnego rozpoznania klinicznego w zaawansowanym wieku nie zmieni dotychczasowego postępowania. Pacjent nie został zakwalifikowany do postępowania zabiegowego, nadal otrzymuje leczenie objawowe pod nadzorem kardiologicznym.

Powyższy przypadek został przedstawiony jako rzadko spotykana konfiguracja - pełen ring utworzony przez funkcjonujące naczynia - a ponieważ obserwowanym i niepokojącym objawem była duszność, prawidłowe rozpoznanie uzyskano w wyniku diagnostyki pulmonologicznej. 


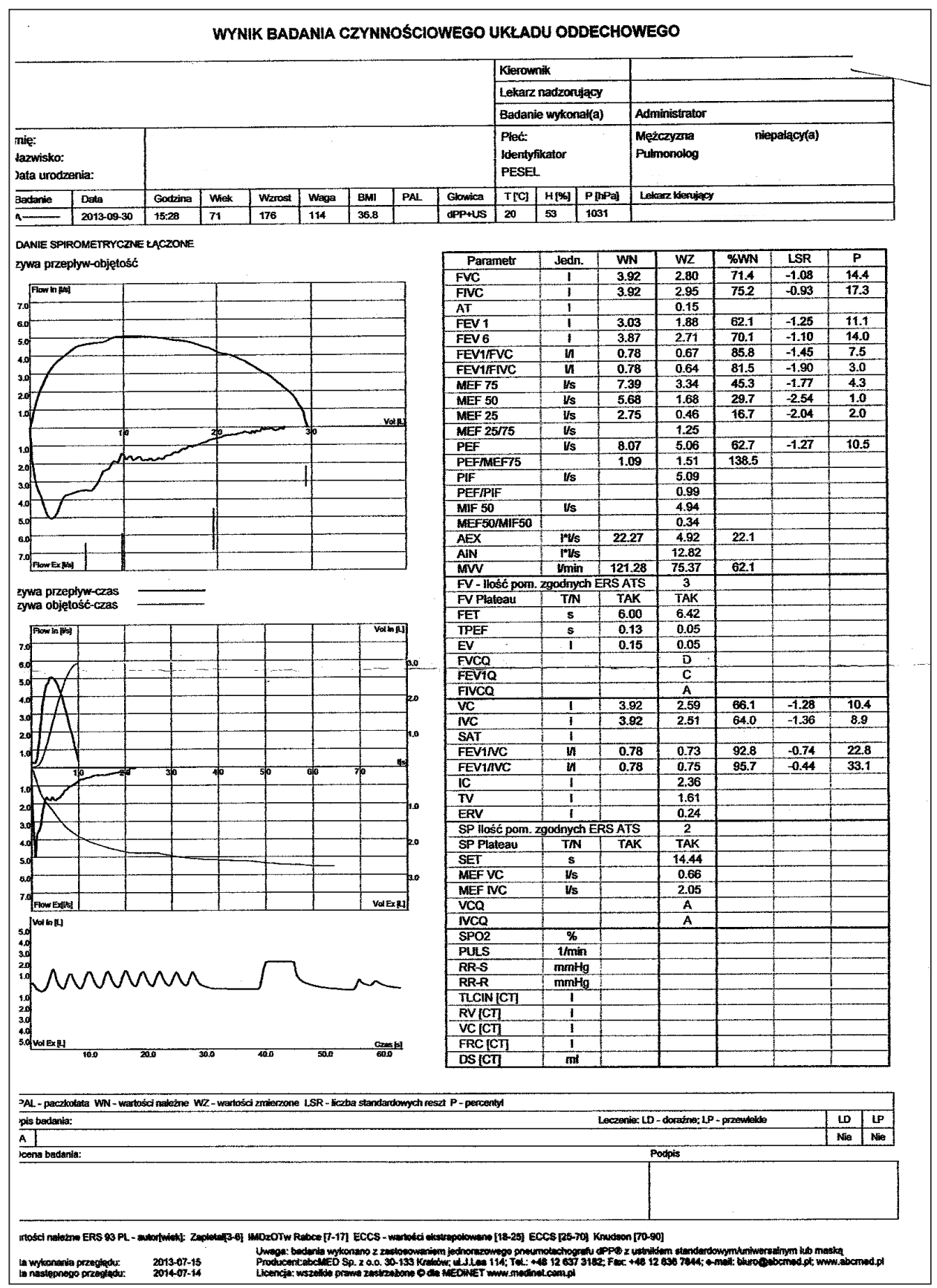

Rycina 3. Badanie czynnościowe układu oddechowego pacjenta

Figure 3. Pulmonary function test

\section{Konflikt interesów}

Autorka deklaruje brak konfliktu interesów.

\section{Piśmiennictwo}

1. Gross R.E. Surgical relief for tracheal obstruction from vascular ring. N. Eng. J. Med. 1945; 233: 586-590.

2. Gross R.E. Arterial malformations which causa compression of the trachea or esophagus. Circulation 1965; 11: 124-134.

3. Edwards J.E. Anomalies of the derivation of the aortic arch system. Med. Clin. N. Amer. 1948; 32: 9-25.

4. Vidne B., Garti I., Rosenber V., Levy M.J. Aortic arch anomalies: simplified clasification. Chest 1972; 62: 39-44.
5. Skalski J.H., Wites M., Haponiuk I. Pierścienie naczyniowe. Kardiochirurgia naczyniowa. Wydawnictwo Naukowe Śląsk, Katowice 2002; 361-378.

6. Foryś S., Słodki M., Janiak K. i wsp. Podwójny łuk aorty u płodu i noworodka, korelacje morfologiczne - opis przypadku kardiologicznego Polska Kardiologia Prenatalna 2011; 09: 1-5

7. Gui-qin Ma., Hong-zhi Li., Xiao-feng Li. i wsp. Congenital vascular rings: a rare cause of respiratory distress in infants and children. Chin. Med. J. 2007; 120: 1408-1412.

8. Jae-Wook R. Complete Vascular ring caused by Kommerell's diverticulum and right aortic arch with mirror image branching. Korean. J. Thorac. Cardiovascular. Surg. 2012; 45: 338-341.

9. Majid Y., Warade M., Aziz. Z., Karthik G.A. Double aortic arches, esophageal atresia and tracheal compresion. J. Indian. Assoc. Pediatr. Surg. 2009; 14: 70-72. 
10. Rios-Mendez R.E., Arauz-Martinez M.E. Chronic wheezing child and type "D"double aortic arch: case report. Arch. Argent. Pediatr. 2008; 106: 481-485.

11. Hickey E.J, Khan A., Anderson D., Lang-Lazdunski L. Complete vascular ring presenting in adulthood An unusual management dilemma. J. Thorac. Cardiovascular. Surg. 2007; 134: 235-236.

12. Miyamoto Y., Ohashi A., Ishi H., Tazaki G., Kondo T. A case of severe bronchial stenosis caused by vascular ring in an elderly woman. Nihon Kokyuki Gakkai Zasshi, 2008; 46: $243-247$.
13. Ikenouchi H., Tabei F., Itoh N., Nozaki A. Silent double aortic arch found in an elderly man. Circulation 2006; 114: 360-361.

14. Kypson A.P., Anderson C.A., Rodriguez E., Koutlas T.C. Double aortic arch in an adult undergoing coronary bypass surgery: a therapeutic dilemma? Eur. J. Cardiothoracic Sur. 2008; 34: 920-921.

15. Kindler H., Bagger JP, Tait P. i wsp. A vascular ring without compression; double aortic arch presenting as a coincidental finding during cardiac catheterization. Heart 2005; 91: 773.

16. Inami T., Seino Y., Mizuno K. Images of vascular ring with a right aortic arch and Kommerell diverticulum obtained by three-dimensional CT. Heart Asia 2012; 4: 110-111. 